Fisher, K. W. (1957). J. gen. Microbiol. 16, 136-145.

\title{
The Nature of the Endergonic Processes in Conjugation in Escherichia coli K-12
}

\author{
By K. W. FISHER \\ Department of Bacteriology, Postgraduate Medical School of London, \\ London, W. 12
}

SUMMARY: The energy required during zygote formation was found to be needed solely by the donor parent. The free energy is utilized by the donor cell in the establishment of effective contacts and subsequently in the transfer of the genetic material to the F - cell. Energy is not required to hold the cells in contact throughout the mating process. The effect of $\mathrm{pH}$ value on the recombination rate is described.

Zygote formation in Escherichia coli $\mathrm{K}-12$ is an endergonic process which is probably not dependent on protein or nucleic acid synthesis (Fisher, 1957). This paper describes an analysis of zygote formation in order to establish more precisely the nature of the endergonic stages.

\section{METHODS}

The materials and bacterial strains used have been described previously (Fisher, 1957). In the present experiments, however, beef-digest broth was replaced by casein hydrolysate yeast extract broth (CHYE) (Difco 'Casamino acids', Technical, $2 \%(\mathrm{w} / \mathrm{v})+$ Difco dehydrated yeast extract, $0.5 \%(\mathrm{w} / \mathrm{v})$; $\mathrm{pH}$ value adjusted to 7-4). Escherichia coli K-12, strains 58-161 Hfr (Hayes, 1953) and W-1 F - (Lederberg \& Lederberg, 1952) were used exclusively.

The methods used to grow the parent cultures and to detect the formation of zygotes were as described by Fisher (1957). Other experimental procedures varied with the demands of particular experiments and will be described in their proper place in the text.

\section{RESULTS}

It was shown (Fisher, 1957) that free energy is required for zygote formation. An analysis of this energy requirement must first resolve whether the energy is required by one or both parents and, secondly, the particular stage or stages of conjugation which are endergonic.

\section{The energy requirements of each parent during conjugation}

Though optimal zygote formation occurs in buffer + glucose + aspartate, zygotes are still formed at a low rate in unsupplemented buffer. It was thought that the low rate which occurred in buffer might be due to endogenous carbohydrate reserves of the bacteria. The effect of starvation on washed parent cells was therefore investigated. The cells were differentially depleted of their carbohydrate or nitrogenous reserves by aeration at $37^{\circ}$ in buffer supplemented 
with ammonium chloride or with glucose, respectively. Depletion of nitrogenous material of either or both parents did not decrease the recombination rate. The effect of carbohydrate depletion is shown in Table 1. It is clear that carbohydrate depletion of the $\mathrm{Hfr}$ parent alone affected the rate of zygote

\section{Table 1. The effect of starvation of parent organisms on zygote formation}

Parent cells were grown aerobically and starved by aerating in buffer (pH $7 \cdot 2$ ) at $37^{\circ}$ for $2 \mathrm{hr}$. Starved and unstarved cells were mated for $30 \mathrm{~min}$. at $37^{\circ}$ in $0.05 \mathrm{M}-$ phosphate buffer (pH 7.2) and then the mixtures assayed for the number of $\mathrm{T}+\mathrm{L}+$ recombinants by diluting the zygote suspension $\left(2 \times 10^{-4}\right)$ and plating triplicate samples on minimal agar supplemented with thiamine and glucose.

Cross
Hfr starved $\times F-$ starved
Hfr starved $\times F-$ unstarved
Hfr unstarved $\times F-$ starved
Hfr unstarved $\times F-$ unstarved

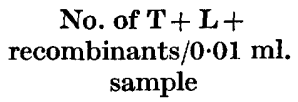

formation; the recipient $\mathrm{F}$ - parent displayed no requirement for energy during conjugation. Such a distinction between the parent strains is of interest since it parallels the differentiation by Hayes (1952) of donor and recipient strains, recently confirmed by the elegant experiments of Wollman \& Jacob (1955) on the inheritance of lambda prophage, and the direct observations of Lederberg (1956).

\section{The energy-requiring stages of zygote formation}

Zygote formation in Escherichia coli has been subdivided into a stage of effective contact between donor $(\mathbf{H f r})$ and recipient $(\mathbf{F}-)$ cells, followed by the transfer of genetic material (Wollman \& Jacob, 1955; Jacob \& Wollman, 1955). 'These workers showed that genetic transfer is effected by the penetration of the $\mathbf{F}$ - cell by a specific extremity of the Hfr chromosome which is then followed by other genetic loci in the same sequence as their arrangement along the chromosome. When mating cells are separated at intervals of time by a Waring Blendor it is found that the Hfr selective markers which control threonine and leucine independence $(\mathbf{T}+\mathbf{L}+)$ enter the $\mathbf{F}-$ cells $(\mathbf{T}-\mathbf{L}-$ ) after a lag of $c .8 \mathrm{~min}$. after mixing the parent cells. When mating cells are separated at this time it is found that prototrophic recombinants $(\mathbf{T}+\mathbf{L}+)$ have inherited few or none of the unselected markers of the Hfr parent. As with $\mathbf{T}+\mathbf{L}+$, there is a characteristic time at which the unselected loci first begin to be detectable among $\mathrm{T}+\mathrm{L}+$ recombinants. Thus, about 9 min. after mixing, the Hfr locus for resistance to sodium azide $\left(\mathbf{A z} \mathbf{z}^{\mathbf{r}}\right)$ begins to appear; resistance to phage $T_{1}\left(T_{1}^{r}\right)$ appears at $10 \mathrm{~min}$; ability to ferment lactose $\left(\mathrm{Lac}_{1}+\right)$ and galactose $\left(\mathrm{Gal}_{\mathrm{b}}+\right)$ appears at 18 and $28 \mathrm{~min}$. respectively. In the $\mathrm{Hfr} \times \mathrm{F}$ - cross only part of the Hfr chromosome is transferred and this is completed in about $\mathbf{3 0} \mathrm{min}$. These findings have been confirmed by using virulent phage specifically to kill the Hfr parent instead of separating the mating pairs by agitation (Hayes, 1957). 


\section{Investigation of the lag period}

In a medium which supports zygote formation use of the Waring Blendor or of virulent phage can only give information about zygote formation subsequent to the time at which the first and succeeding Hfr loci enter the F cell and allow the formation of detectable recombinants. An attempt was made to investigate the earlier stages of zygote formation with the specific

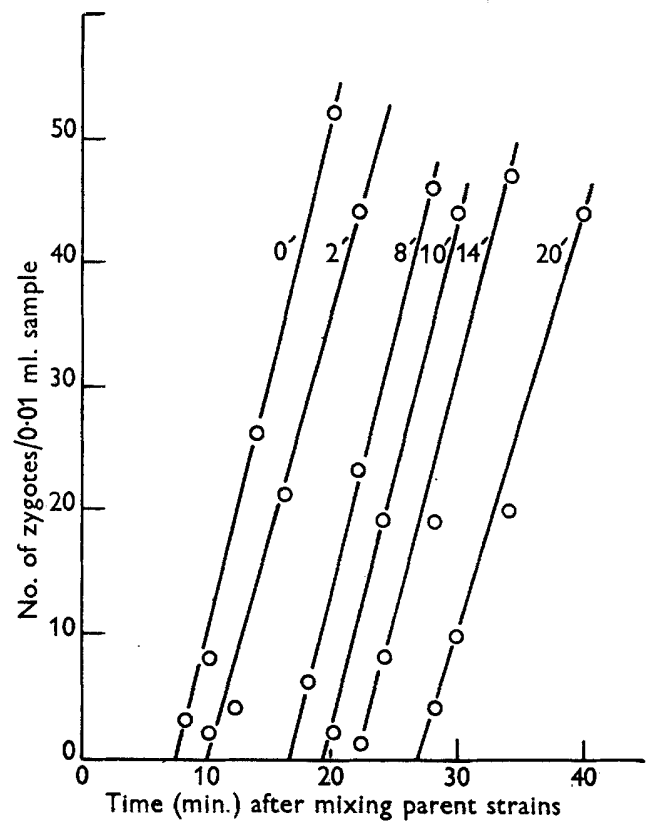

Fig. 1. The effect of an initial anaerobic period on zygote formation. Washed suspensions of

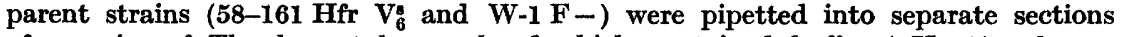
of a series of Thunberg tubes each of which contained buffer ( $\mathrm{pH} \mathrm{6.5)}+$ glucose $(20 \mu \mathrm{mole} / \mathrm{ml}$.) + sodium aspartate (equivalent to $80 \mu \mathrm{g} . / \mathrm{ml}$.) free acid. After flushing with nitrogen the tubes were evacuated, sealed and warmed to $37^{\circ}$ before mixing the contents. Each tube in turn was oxygenated and thereafter sampled at intervals for the number of $T+L+$ recombinants. The figures on the curves indicate the time after mixing at which oxygen was admitted to the mixtures.

aim of detecting stages which might occur in the absence of available free energy. Since oxygen is required for zygote formation (Fisher, 1957), the simplest approach. to this problem was to see whether any step preceding detectable genetic transfer would occur under anaerobic conditions. A series of identical suspensions of $\mathbf{H f r}$ and $\mathbf{F}$ - cells in buffer + glucose + aspartate were mixed and shaken gently in Thunberg tubes at $37^{\circ}$ under anaerobic conditions (Fisher, 1957). The tubes were oxygenated in turn at intervals after mixing. Thereafter samples were removed at intervals and assayed for the number of zygotes formed as shown by the number of $\mathbf{T}+\mathrm{L}+$ recombinants present by using a modification of the phage method (see below); the results are shown in Fig. 1. It can be seen that all the curves which describe the rate of zygote formation are parallel, but each is displaced from the control 
curve (oxygenated at zero time) by an interval of the same duration as the anaerobic period which preceded oxygenation. This shows that under anaerobic conditions nothing happened which affected the efficiency of subsequent conjugations, although the probability of collision was the same as in the presence of oxygen. From this it is concluded that zygote formation is an energyrequiring process from its inception, so that the formation of effective contacts is endergonic.

\section{Effect of $\mathrm{pH}$ value on recombination}

Arising from observations associated with the penetration of dicarboxylic acids into parent cells (Fisher, 1957), the effect of the $\mathrm{pH}$ value of the environment on the recombination rate was investigated. To avoid complications due to ionizable substrates (dicarboxylic acids) the determinations were carried out in unsupplemented buffer where the mating processes are forced to rely

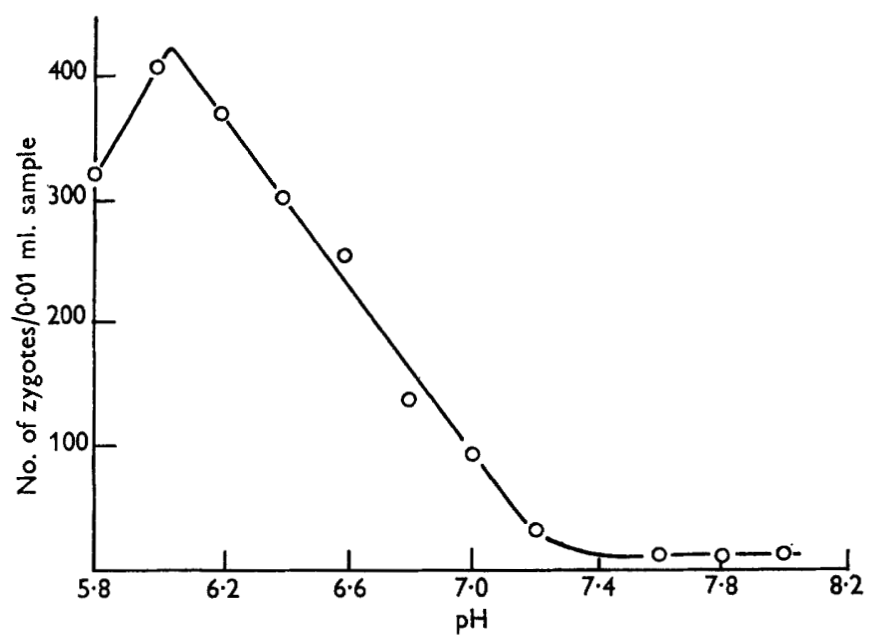

Fig. 2. The effect of $\mathrm{pH}$ value of medium on zygote formation between strains 58-161 $\mathrm{Hfr}$ and W-1 F-. Parent organisms were washed separately with $0 \cdot 05 \mathrm{M}$-phosphate buffer (pH 7.2) and then resuspended and mixed in $0.05 \mathrm{M}-\mathrm{phosphate}$ buffer containing $0.4 \%(\mathrm{w} / \mathrm{v}) \mathrm{NaCl}$ and $0.02 \%(\mathrm{w} / \mathrm{v}) \mathrm{MgSO}_{4} .7 \mathrm{H}_{2} \mathrm{O}$. The $\mathrm{pH}$ values of the buffers were accurately adjusted (Muirhead $\mathrm{pH}$ meter). The mixtures were assayed for the number of zygotes formed after $30 \mathrm{~min}$. incubation at $37^{\circ}$.

on the endogenous reserves of the Hfr cells. Hfr and F - cell suspensions were mixed in $0.05 \mathrm{M}$-phosphate buffer accurately adjusted to different $\mathrm{pH}$ values measured electrometrically. The mixed suspensions were aerated at $37^{\circ}$ for $30 \mathrm{~min}$. and each assayed for the number of zygotes formed; the results are shown in Fig. 2. There were marked differences in the recombination rate at different $\mathrm{pH}$ values. The optimal $\mathrm{pH}$ value for the strains used was $6 \cdot 1$. Since the effect of $\mathrm{pH}$ value in these experiments was unrelated to energy supply, it is most probably ascribable to alterations in the distribution of ionized groups on the surface of the cells. Maccacaro (1955) and Maccacaro \& Comolli (1956) reached the conclusion that surface groupings are intimately concerned with the fertility of $\mathrm{F}+\times \mathrm{F}-$ crosses. 


\section{Chromosome transfer: an endergonic process}

It has been shown above that energy is required for the formation of effective contacts. The question remains, does the energy requirement extend throughout the whole period of zygote formation, i.e. is energy needed by the $\mathrm{Hfr}$ cell for chromosome transfer? The action of a number of inhibitors on zygote formation has been described (Fisher, 1957). Of these substances, 2:4-dinitrophenol (DNP) was chosen for the purpose of determining whether chromosome transfer could be inhibited by the uncoupling of oxidative phosphorylation and free energy utilization. Since the action of DNP is reversible it was found necessary to kill the Hfr cells with phage $\mathrm{T}_{6}$ (Hayes, 1957), to which the $\mathrm{F}-$ cells are resistant, before diluting out the DNP as a preliminary to plating on selective medium for recombinants. Washed parent suspensions were mixed in buffer + glucose + aspartate $(\mathrm{pH} 6.5)$ and aerated at $37^{\circ}$. At intervals thereafter samples were removed to DNP (final conc. $10^{-3} \mathrm{M}$ ) and aerated at $37^{\circ}$. The samples containing DNP were then scored as a function of time for $\mathrm{T}+\mathrm{L}+$ and $\mathbf{T}+\mathrm{L}+\mathrm{Lac}+$ recombinants by treatment with phage $\mathbf{T}_{6}$ followed by dilution and plating on minimal agar + thiamine + glucose $\left(\mathrm{MAB}_{1}\right.$ : selection for $\mathbf{T}+\mathbf{L}+$ only) and on minimal agar + thiamine + lactose $\left(\right.$ MAB $_{1}$ Lac: selection for $T+L+L a c+)$. The results are given in Fig. 3. Curve 1 shows the total number of $\mathbf{T}+\mathbf{L}+$ recombinants found at various times after mixing the parents; curve 5 shows the number of $T+L+L a c+$ recombinants found in the same samples. The horizontal lines represent the number of recombinants of either class arising from samples added to DNP at 10, 15 and 20 min. after mixing. If the effect of adding DNP was to interfere only with effective contact formation and not with transfer, one would expect to find, in any sample, a proportion of pairs of cells which had already made effective contact but in which transfer of $\mathbf{T}+\mathbf{L}+$ had not occurred. If, therefore, DNP did not interfere with chromosomal transfer, the proportion of $\mathrm{T}+\mathrm{L}+$ recombinants should rise after addition of DNP. Furthermore, in the case of those zygotes which had acquired $\mathbf{T}+\mathbf{L}+$ (e.g. curve 2 ) but not Lac + at the time of adding DNP, the proportion of $\mathrm{T}+\mathrm{L}+\mathrm{Lac}+$ recombinants (curve 6 ) should increase. The fact that the curves are horizontal shows that chromosome transfer is inhibited by DNP.

\section{The use of 2:4-dinitrophenol in the analysis of chromosome transfer}

The kinetics of chromosome transfer has been determined by using DNP in combination with phage $T_{6}$. Washed parent suspensions were mixed in buffer + glucose + aspartate ( $\mathrm{pH} \mathrm{6.5)}$ and, at intervals after mixing, samples were removed to DNP (final conc. $10^{-3} \mathrm{M}$ ) and, after a convenient interval, were treated with phage $\mathbf{T}_{6}$. The samples were then diluted and plated on minimal agar + glucose + thiamine $+\mathrm{L}$-leucine $\left(\mathrm{MAB}_{1} \mathrm{~L}\right.$ : selection for $\mathrm{T}+$ transfer only). Control plates of $\mathrm{MAB}_{1} \mathrm{~L}$ spread with double-sized samples of either parent alone showed no growth after incubation. Recombinant clones arising from each sample of the mixture were purified and scored for inheritance from the Hfr parent of the unselected markers: $L+A z^{r} V_{1}^{r} L a c+V_{6}^{a}$. The 
results of these analyses are plotted in Fig. 4. From the time at which it was first detectable, the quantitative increase with time of any particular Hfr gene among the $\mathbf{T}+$ recombinants could be demonstrated. The order of transfer of genes was found to be the same as the order of their arrangement on the chromosome as established by other authors from recombination data (Lederberg, 1947; Cavalli-Sforza \& Jinks, 1956). With the method described here it was possible to separate in time the transfer of the closely linked loci $\mathbf{T}+, \mathbf{L}+$ and $\mathbf{A} \mathbf{z}^{\mathbf{r}}$.

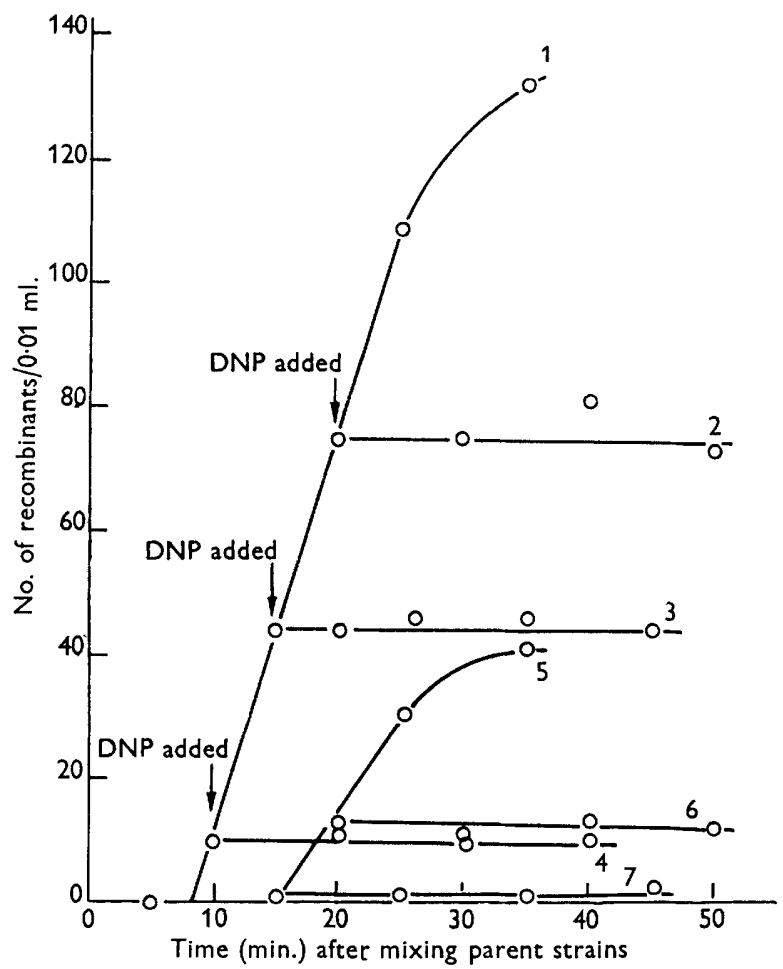

Fig. 3. The effect of 2:4-dinitrophenol on chromosome movement. Suspensions of washed parent cells (58-161 Hfr $V_{6}^{8}$ and $\left.W-1 ~ F-V_{6}^{r}\right)$ were mixed in buffer + glucose + aspartate. At intervals after mixing samples were removed to DNP solution $\left(10^{-3} \mathrm{M}\right)$ and following treatment with phage $T_{6}$ were diluted $\left(2 \times 10^{-4}\right)$ and $0.01 \mathrm{ml}$. samples plated on minimal agar + thiamine + glucose $\left(\mathrm{MAB}_{1}\right.$ : selection for $\mathbf{T}+\mathbf{L}+$ inheritance from the

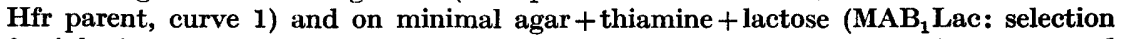
for inheritance of $\mathrm{T}+\mathrm{L}+$ and $\mathrm{Lac}+$ from the Hfr parent, curve 5). At 10, 15 and $20 \mathrm{~min}$. after mixing, larger samples were removed to DNP $\left(1^{-3} \mathrm{M}\right)$ and thereafter subsamples were treated with phage $T_{6}$, diluted and plated on $\mathrm{MAB}_{1}$ (curves 2-4) and on MAB 1 Lac (curves 6 and 7).

\section{The continuity of chromosomal transfer}

Experiments were designed to test the assumption made in this paper and that of Wollman \& Jacob (1955) that the kinetic results obtained reflect the movement of a physical continuum from the donor to the recipient cell. Parent suspensions were mixed in buffer + glucose + aspartate $(\mathrm{pH} \mathrm{6.5)}$ and 
aerated at $37^{\circ}$ for $\mathbf{2 0} \mathrm{min}$. From previous experiments it was known that at this time the Hfr loci $\mathbf{T}+\mathrm{L}+$ had been transferred to the majority of zygotes but that the locus Lac + was only beginning to enter these zygotes. At this point the mixture was cooled to $4^{\circ}$ and diluted $1 / 100$ with buffer + glucose + aspartate at $4^{\circ}$ to prevent further collisions. After $20 \mathrm{~min}$. at $4^{\circ}$ the mixture was rapidly warmed to $37^{\circ}$ and aeration continued. At intervals throughout

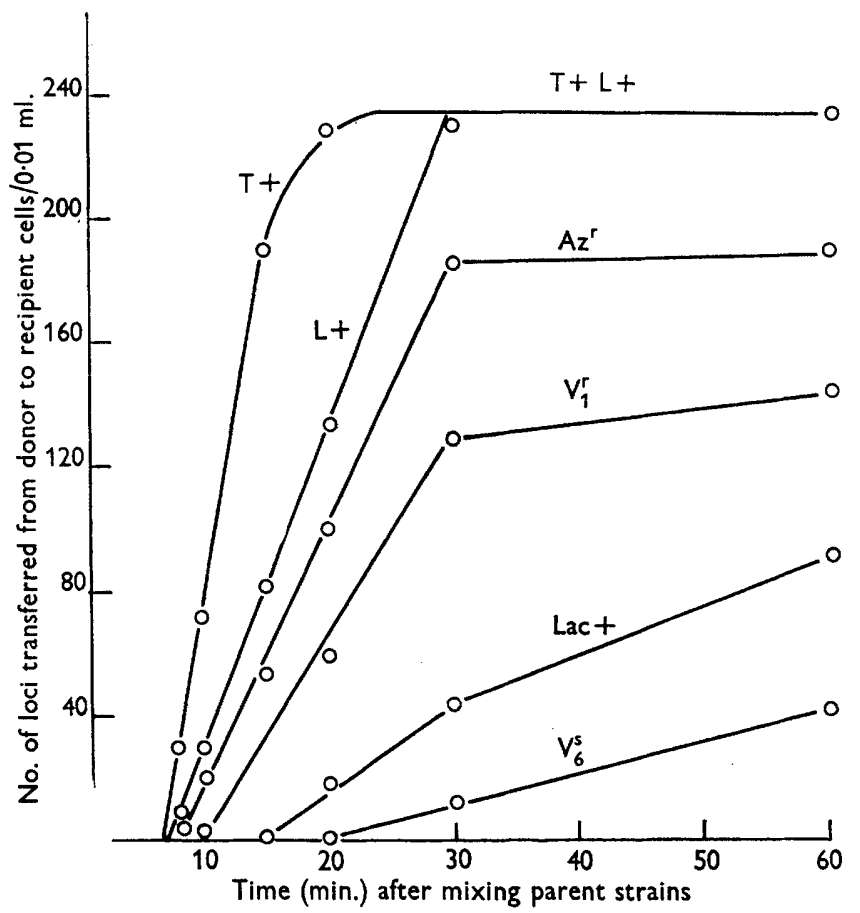

Fig. 4. The variation of recombinant genotype with the period of mating between 58-161 $\mathrm{Hfr}$ and W-1 F-. Washed suspensions of parent cells (58-161 $\mathrm{Hfr} T+\mathrm{T}+\mathrm{B}_{1}+\mathrm{M}-, \mathrm{Az}^{\mathrm{r}}$, $V_{1}^{r}, L_{a c}+, V_{6}^{s}$ and $W-1 F-T-L-B_{1}-M+A z_{1}^{s} V_{1}^{s} L_{1} a c_{1}-V_{6}^{r}$ were mixed in buffer + glucose + aspartate ( $\mathrm{pH} \mathrm{6.5)}$ (see Fig. 1 for substrate concentrations). At intervals after mixing samples were removed to $\mathrm{DNP}\left(10^{-3} \mathrm{M}\right)+$ phage $\mathrm{T}_{6}$ and incubated for $10 \mathrm{~min}$. After dilution triplicate $0.01 \mathrm{ml}$. samples were plated on minimal agar + thiamine + glucose + leucine (selection for $\mathbf{T}+$ inheritance from $\mathrm{Hfr}$ cell). Recombinant clones were purified and examined for the inheritance of unselected markers from the Hfr parent.

the entire period samples were transferred to $\mathrm{DNP}+$ phage $\mathrm{T}_{6}$ and finally plated to assess the number of $\mathbf{T}+\mathrm{L}+$ and of $\mathrm{T}+\mathrm{L}+\mathrm{Lac}+$ recombinants. The results are given in Fig. 5, where it can be seen that increase in all classes of recombinants was completely prevented by cooling. After rewarming the entry of Lac + was resumed at its initial rate. Since, over the same period of time, the number of $\mathbf{T}+\mathbf{L}+$ recombinants increased only slightly, the increase of $\mathbf{T}+\mathbf{L}+\mathrm{Lac}+$ recombinants cannot be explained on the basis of formation of new recombinant pairs. It must, therefore, be due to the subsequent entry of Lac + into zygotes which, at the time of cooling, had 
already acquired $\mathrm{T}+\mathrm{L}+$ but had not separated during the period at $4^{\circ}$. This experiment confirms the results obtained with DNP and rules out the possibility that energy is also required to hold the cells in contact throughout transfer.

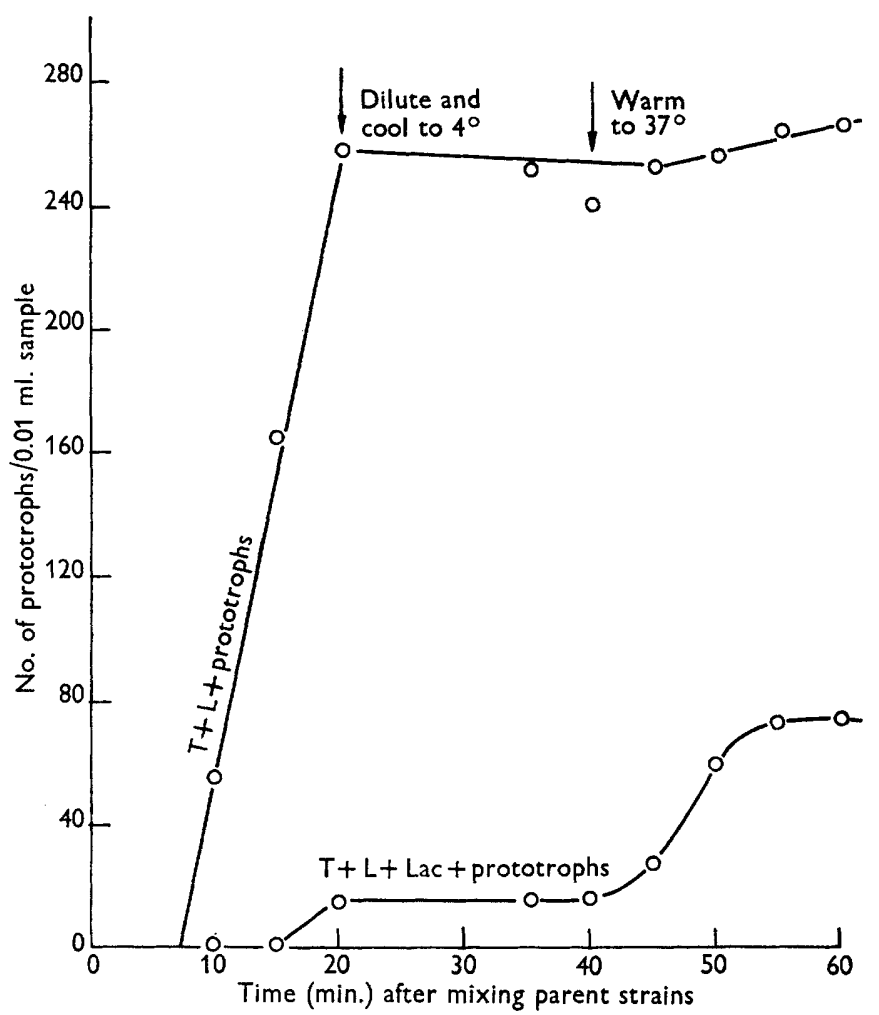

Fig. 5. The continuity of chromosomal transfer. Washed suspensions of 58-161 Hfr $\left(M-L a c+V_{6}^{s}\right)$ and $W-1 ~ F-\left(T L B_{1}-L a c-V_{6}^{r}\right)$ were mixed in buffer + glucose + aspartate $\left(\mathrm{pH} \mathrm{6.5)}\right.$ and aerated at $37^{\circ}$ for $20 \mathrm{~min}$. The mixture was then cooled to $4^{\circ}$ and diluted $1 / 100$ in buffer + glucose + aspartate at $4^{\circ}$. After 20 min the mixture was rapidly warmed to $37^{\circ}$ and aeration at $37^{\circ}$ continued. Samples were removed at intervals to DNP + phage $T_{6}$ and then diluted $\left(2 \times 10^{-4}\right)$ and $0.01 \mathrm{ml}$. samples plated in triplicate on: (1) minimal agar + thiamine + glucose (selection for inheritance of $\mathbf{T}+\mathbf{L}+$ only from the Hfr parent); (2) minimal agar + thiamine + lactose (selection for inheritance of $\mathbf{T}+\mathbf{L}+$ and Lac + from the Hfr parent).

\section{DISCUSSION}

It has been shown that energy is required for zygote formation (Fisher, 1957). This energy is utilized only by the donor cells in both $\mathrm{Hfr}$ and $\mathrm{F}+$ crosses with $\mathbf{F}$ - cells. Thus the $\mathbf{F}$ - cells play a passive role during this stage of the mating process, although, later, they must be responsible for supporting the stages of recombination and segregation. Zygote formation comprises everything that happens from the initial collision between donor and recipient cells until the completion of chromosome transfer. The ability of donor and recipient cells to form an intimate contact following collision is probably 
decided by their surface configurations (Maccacaro, 1955; Maccacaro \& Comolli, 1956). The effect of $\mathrm{pH}$ value of the suspending fluid in altering the recombination rate thus becomes understandable if it exercises a surface effect which may alter the mutual attraction between the cells. It has been shown (Hayes, 1957) that alteration in $\mathrm{pH}$ value has the same effect on the mating process as variation in population density, which only affects the rate of collision and is not related to energy-requiring processes. The effect of the $\mathrm{pH}$ value of the medium is, therefore, probably to increase the proportion of collisions which are followed by adherence.

However, in the absence of a supply of free energy no spontaneously irreversible step in conjugation takes place, i.e. energy is required for the formation of effective contacts. The fact that energy is also required for chromosome transfer raises the question whether the irreversible link uniting the cells is really the chromosome itself. Electron microphotographs show the presence of a bridge of material between conjugating cells (Wollman, Jacob $\&$ Hayes, 1956). This bridge is clearly not the chromosome, as the absence of effect of DNA-ase on recombination had already suggested (Lederberg, 1947; Hayes, 1957). The appearance of some of these bridges implies that they must exercise some uniting force between the pairs of cells, and it might be suggested that the energy required for effective contact formation is utilized in making them. Against this is the finding that chloramphenicol, which inhibits protein synthesis in Escherichia coli (Wissemann, Smadel, Hahn \& Hopps, 1954), does not appear to inhibit zygote formation (Fisher, 1957). These experiments may, however, be criticized, since the chloramphenicol was only added to the mating cells at the time of mixing. Curves expressing the rate at which effective contacts are formed arise from the origin (Wollman \& Jacob, 1955) so that this essential step of the mating process must be accomplished very rapidly. It is therefore possible that effective contacts had been formed before protein synthesis was arrested. It seems clear, however, that protein synthesis is not essential to chromosome transfer.

The work was carried out whilst in receipt of a personal grant from the British Empire Cancer Campaign. I wish to express my thanks to Professor Lord Stamp for the facilities extended to me during the course of the work and to Dr W. Hayes for his suggestions and help at all stages of the work. The work forms part of a Ph.D. thesis presented to the University of London.

\section{REFERENCES}

Cavalli-Sforza, L. L. \& Jinks, J. L. (1956). Studies on the genetic systems of Escherichia coli K-12. J. Genet. 54, 87.

Fisher, K. W. (1957). The role of the Krebs cycle in conjugation in Escherichia coli K-12. J. gen. Microbiol. 16, 120.

Hayes, W. (1952). Recombination in Bacterium coli K-12: unidirectional transfer of genetic material. Nature, Lond. 169, 118.

HAYES, W. (1953). The mechanism of genetic recombination in Escherichia coli. Cold Spr. Harb. Symp. quant. Biol. 18, 75.

Hayes, W. (1957). The kinetics of the mating process in Escherichia coli. J. gen. Microbiol. 16, 97. 
$\mathbf{J}_{\text {AcoB, }}$ F. \& Wollman, E. (1955). Étapes de la recombinaison génétique chez Escherichia coli K-12. C.R. Acad. Sci., Paris, 240, 2566.

LEDERBERG, J. (1947). Gene recombination and linked segregations in Escherichia coli. Genetics, 32, 505.

Lederberg, J. (1956). Conjugal pairing in Escherichia coli. J. Bact. 71, 497.

Lederberg, J. \& Lederberg, E. M. (1952). Replica plating and indirect selection of bacterial mutants. J. Bact. 63, 399.

Maccacaro, G. A. (1955). Cell surface and fertility in Escherichia coli. Nature, Lond. 176, 125.

Maccacaro, G. A. \& Comolli, R. (1956). Surface properties correlated with sex compatability in Escherichia coli. J. gen. Microbiol. 15, 131.

Wisseman, C. L., Smadel, J. E., Hahn, F. E. \& Hopps, H. E. (1954). Mode of action of chloramphenicol. I. Action of chloramphenicol on assimilation of ammonia and on synthesis of proteins and nucleic acids in Escherichia coli. J. Bact. 67, 662.

Wollman, E. L. \& J Jcob, F. (1955). Sur le mécanisme du transfert de matériel génétique au cours de la recombinaison chez Escherichia coli K-12. C.R. Acad. Sci., Paris, 240, 2449.

Wollman, E. L., JACOB, F. \& HAYES, W. (1956). Conjugation and genetic recombination in Escherichia coli K-12. Cold Spr. Harb. Symp. guant. Biol. 21 (in the Press).

(Received 11 July 1956) 